INTERNATIONAL DESIGN CONFERENCE - DESIGN 2018

https://doi.org/10.21278/idc.2018.0359

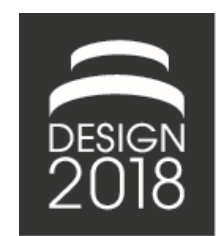

\title{
COMPARATIVE ANALYSIS OF RESEARCH FOR INDUSTRIAL DESIGN AND ENGINEERING DESIGN BASED ON MULTISPACE DESIGN MODEL
}

\author{
Y. Sakae, S. Mukai, K. Sato and Y. Matsuoka
}

\begin{abstract}
This research conducts comparative analysis of domestic and international articles for industrial design and engineering design domains to clarify the characteristics of the two design domains, as well as to derive the future issues for design integration. Various articles from the domestic and international societies were extracted and were evaluated from the viewpoint of multispace design model. In addition, the future issues for facilitating the design integration between industrial designers and engineering designers were investigated.
\end{abstract}

Keywords: industrial design, engineering design, collaborative design, multispace design model, design science

\section{Introduction}

Along with the industrial revolution in the late $18^{\text {th }}$ century and development of science and technology, the subdivision of design between industrial designers, mainly focusing on appearance of artifacts from a viewpoint of art, and engineering designers who place their eyes on mechanical functions of artifacts, has occurred (Hosnedl et al., 2008). During the $19^{\text {th }}$ century, there was expansion and specialization of each design domain, through on one hand promoting industrial design studies at Bauhaus, and on the other hand developing the technology of architectural analysis and optimization with the advancement of computers. While these subdivision and specialization have created society with low-cost and highquality artifacts, they have also risen scales and complexities. In addition, the possibility of casualties and human errors have increased, leading to emergence of serious social issues (e.g. critical accidents of nuclear energy plants, global warming, and environmental pollution caused by massive consumption and disposal) (Matsuoka, 2012). Moreover, through the rapid development of information technology in the $21^{\text {st }}$ century, individual values have diversified, and the number of design elements and requirements have increased (Matsuoka, 2010). Therefore, industrial designers and engineering designers are expected to correspond to all of these social issues, as well as to manage the diversity of individual values in a collaborative manner (McMahon, 2012; Kim and Lee, 2016).

However, it can hardly be said that industrial design and engineering design are on their process of accommodating the issues, because enormous amount of information and knowledge obtained in both design domains are not being shared enough across each other (Persson and Warell, 2003). Although each domain knows their appropriate conditions to apply their own information and knowledge, many of industrial designers and engineering designers are not grasping how to apply them in the field of the other domains. Specifically, according to subdivision and specialization, each design domain has developed their own theories and methodologies individually, whereas common basic ground or foundation crossing the design domains has not been built enough (Kim and Lee, 2010). Additionally, 
for the reason of unknowing appropriate methods to apply their information and knowledge within the other design domains, industrial designers and engineering designers are struggling with accommodating the aforementioned issues. Therefore, comprehensive researches on the characteristics of both domains, along with the establishment of principles of design integration between industrial designers and engineering designers are crucial. However, such studies have not been conducted enough (Kim and Lee, 2014).

This research has two objectives. First, we aim to clarify the characteristics of industrial design and engineering design by analyzing the domestic and international research for the both domains. Second, we investigate the future research issues for the design integration between industrial designers and engineering designers. To analyze the articles, multispace design model, a model which enables to comprehensively analyze various types of designing, is applied as an evaluation criteria. Along with the characteristics extraction of domestic and international research for industrial design and engineering design, the future issues for design integration are derived.

\section{Multispace design model}

The multispace design model is a framework for design theory developed by Matsuoka (2010) that can comprehensively acknowledge all types of design procedures. The basis comes from the general design studies of Yoshikawa $(1979,1981,1985)$, and have been expanded so that the multispace design model can consider concepts such as value, meaning, and circumstance of artifacts. When designing, elements which constitute artifacts are divided into thinking space, and the relation of these elements extract a novel design. Because the multispace design model can assess elements comprehensively, herein it is used to analyze the characteristics and relations of industrial design and engineering design.

As shown in Figure 1, the multispace design model is composed of thinking space and knowledge space, enabling logical reasoning of design practices through design processes.

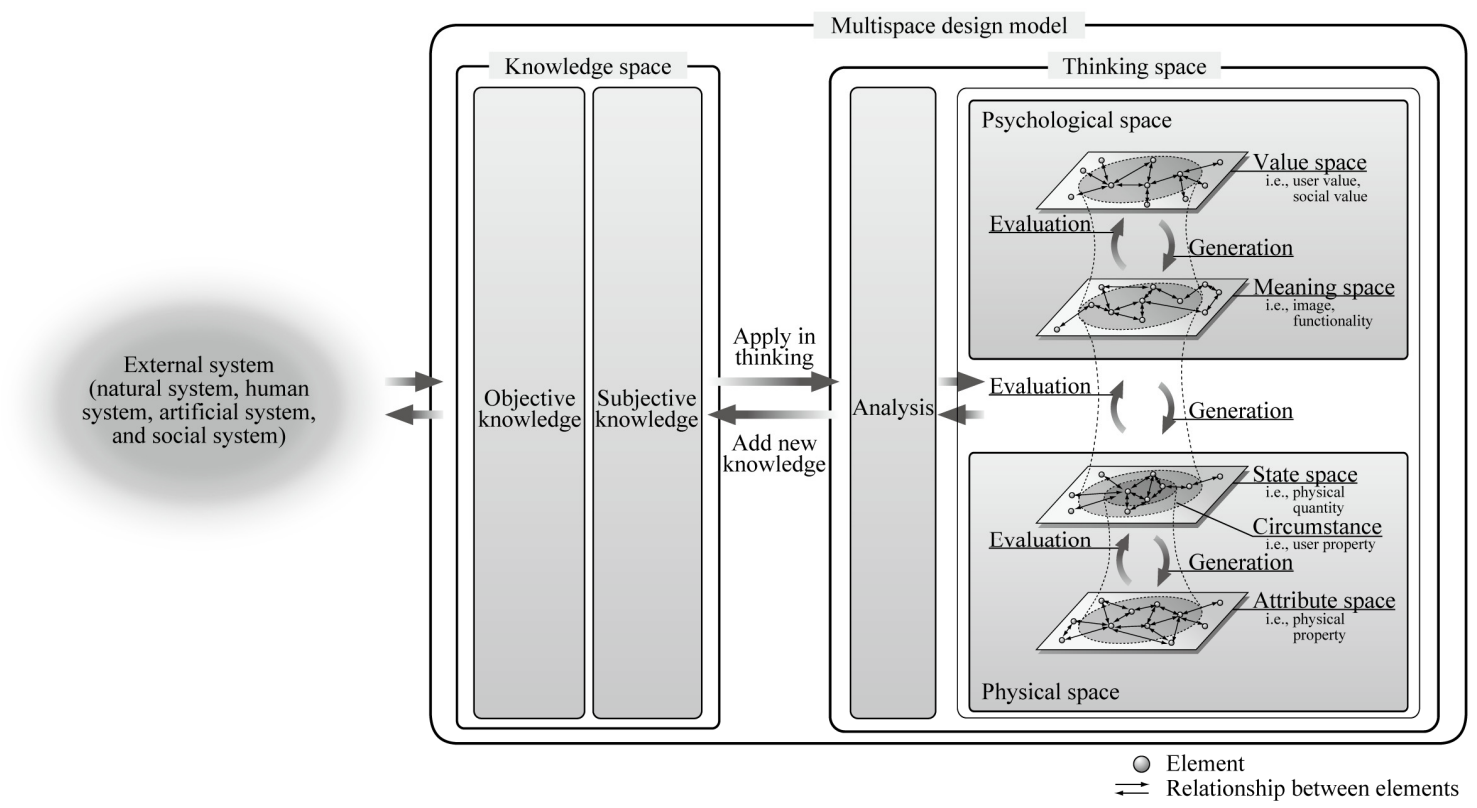

Figure 1. Multispace design model

The thinking space is where elements of a design object, and design acts employed to handle each element are described. It is comprised of four spaces and "AGE thinking". The four spaces are value space, meaning space, state space, and attribute space. First, the value space consists of elements relating to various values (e.g., social, cultural, and personal values). Second, the meaning space consists of elements relating to artifacts functionality and image. Third, the state space consists of elements relating to dynamical, electrical, and chemical characteristics. Fourth, the attribute space consists of elements relating to artifacts traits which are unaffected by the surroundings. The value space and the meaning 
space can be classified as psychological space, whereas the state space and the attribute space can be classified as physical space. For example, in the case of designing a chair, "comfort" and "sense of fitting" are classified as the psychological elements, while "deflection" and "material" are classified as the physical elements.

The relations between every element are expressed based on AGE thinking: a framework proposed in design science (Matsuoka, 2008), originating from the design thinking model of J. Christopher Jones, L. Bruce Archer, and Lionel March (Jones, 1970; Paul, 2007; Cross, 2008). It constitutes three common acts, which are repeatedly performed during design processes: induction-based analysis, abductionbased generation, and deduction-based evaluation (Figure 2). Specifically, an industrial designer/engineering designer initially analyzes the current conditions and the phenomenon of a design problem. Then the results are used to generate a number of design elements that would solve the design problem. In addition, each design element is evaluated using the results derived from the analysis. If the elements are inadequate for the design problem, the industrial designer/ engineering designer reanalyzes the problem and generates design elements over again until the proper design solution is derived.

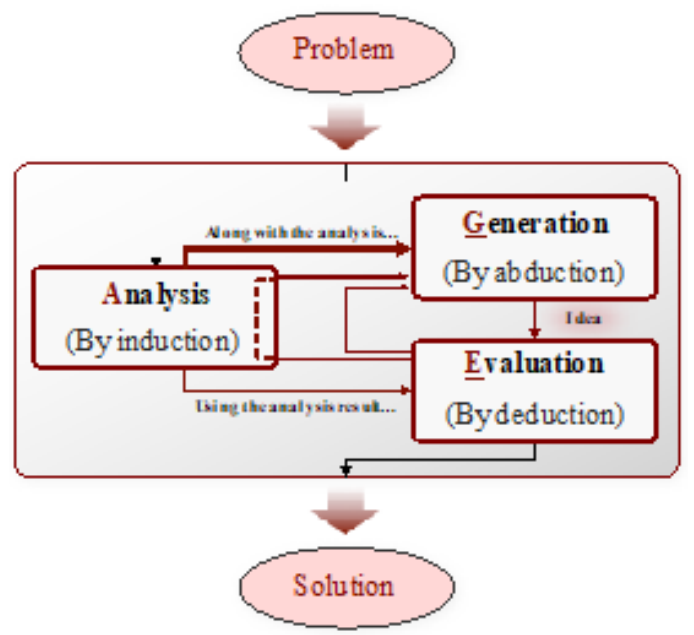

Figure 2. AGE thinking model

The knowledge space is where design knowledge applied to AGE thinking is expressed. It is comprised of two main types of knowledge: objective and subjective knowledge. The objective knowledge space consists of general knowledge, such as design theories and methodologies relating to natural science, social science, humanities, liberal arts, etc. On the other hand, the subjective knowledge space is comprised of one's own set of values gained from experience or regional culture. For example, in the case of designing a chair, the theory of ergonomics is classified as the objective knowledge, while one's intuition for deciding the most satisfying solution against user requirements, is classified as the subjective knowledge.

\section{Relations between industrial design and engineering design}

The studies on thought experiment and processes in the industrial design and the engineering design show each of their characteristics as follows (Lee, 1995):

The characteristic of the industrial design is that objective and constraint condition are often indistinct. Therefore, objective becomes clear in consideration of psychological elements including demands of users and social trend. At the same time, in consideration of physical elements including configurations and color, diverse solution candidates to the indistinct objective. Then the solutions are derived by evaluation of solution candidates. Accordingly, the psychological elements relations are mainly handled in the industrial design. In addition, diverse solutions are derived through interactive consideration of elements.

On the other hand, the characteristic of the engineering design is that objective and constraint condition including function and performance are often clear. Thus, the solutions are derived in consideration of 
physical elements, including mechanisms and materials, to perform the function. Particularly, in case the problems can be quantified, optimum solutions are derived with optimization approach. Hence, the relations of physical elements are mainly handled in the engineering design. In addition, optimum solutions including configurations and setting angles are derived in unidirectional consideration of elements.

When comparing the industrial design with engineering design, the characteristics of the former are often seen in the early process of designing while the characteristics of engineering design mainly appear in the late process. Here, Figure 3 describes the characteristics of processes in the industrial design and the engineering design with the multispace design model. Typically, in the early process of designing, industrial designers often interactively deal with psychological elements and physical elements, while in the late process, engineering designers unidirectionally deals with physical elements. Consequently, the elements that are mainly handled as well as the methodological characteristics in the industrial design and the engineering design are comprehensively described with the multispace design model. This identifies that a comparative analysis of research for each design domain can be carried out from the viewpoint of the multispace design model.

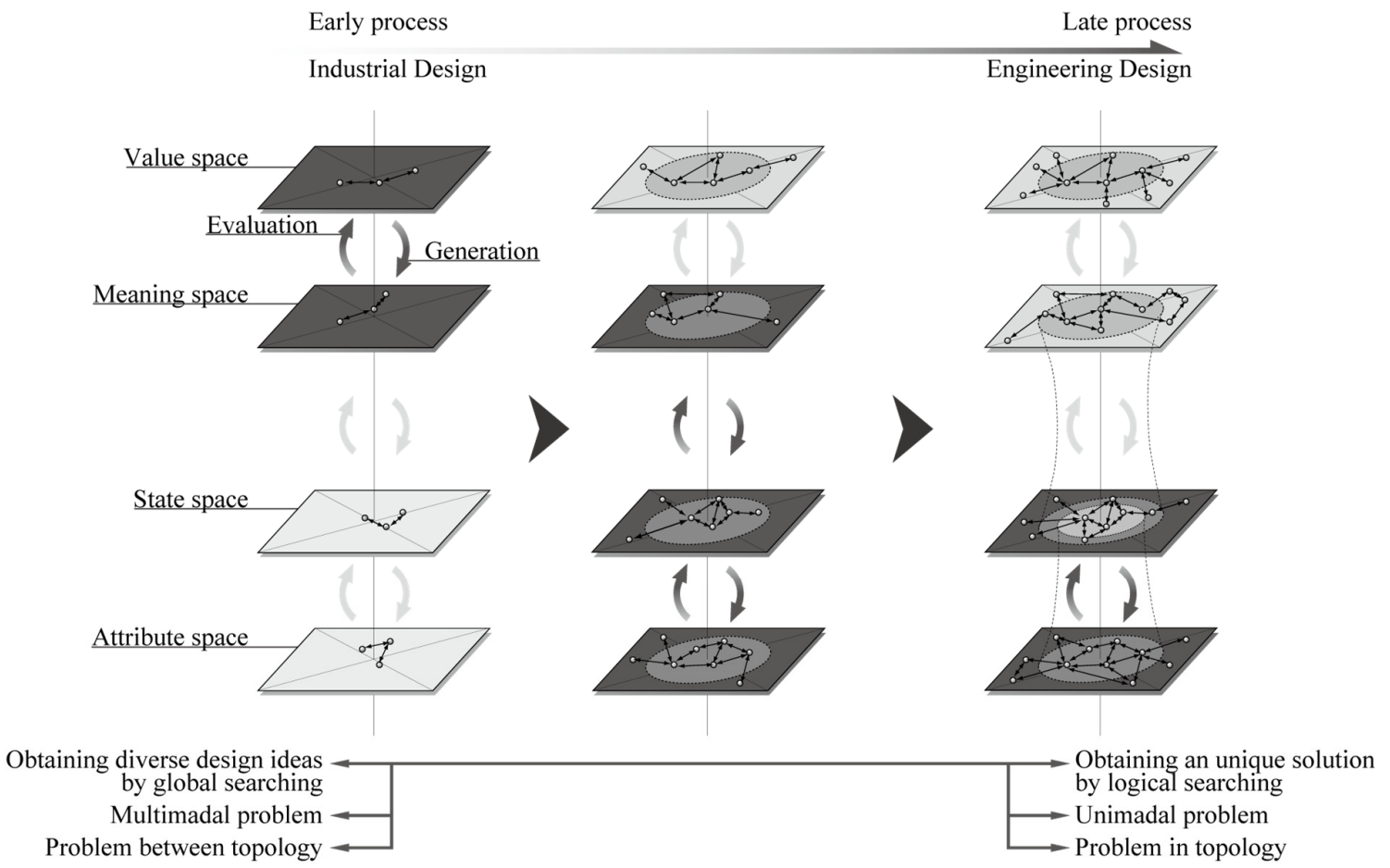

Figure 3. Relations between industrial design and engineering design

\section{Research approach}

\subsection{Data collection}

In this research, the articles published from the domestic and international representative societies for industrial design and engineering design during 2011 to 2015 were extracted as the raw data of theevaluation. Specifically, 224 articles were collected from Bulletin of JSSD published by JSSD (Japanese Society for the Science of Design), while 183 articles were collected from Transactions of the $J S M E$ published by JSME (The Japan Society of Mechanical Engineers). On the other hand, 152 articles were collected from Design Studies published by DRS (Design Research Society), and 155 articles were collected from Journal of Engineering Design published by The Design Society. In sum, 714 articles were extracted for clarifying the characteristics of the research for the both domains (Table 1). 
Table 1. Number of articles

\begin{tabular}{|c|c|c|c|c|}
\hline \multirow[b]{3}{*}{ Year } & \multicolumn{4}{|c|}{ Number of articles } \\
\hline & \multicolumn{2}{|c|}{ Domestic } & \multicolumn{2}{|c|}{ International } \\
\hline & $\begin{array}{l}\text { Industrial design } \\
\text { (Bulletin of JSSD) }\end{array}$ & $\begin{array}{l}\text { Engineering design } \\
\text { (Transaction of the } \\
\text { JSME) }\end{array}$ & $\begin{array}{l}\text { Industrial design } \\
\text { (Design Studies) }\end{array}$ & $\begin{array}{c}\text { Engineering design } \\
\text { (Journal of Engineering } \\
\text { Design) }\end{array}$ \\
\hline 2011 & 52 & 27 & 27 & 37 \\
\hline 2012 & 39 & 33 & 29 & 42 \\
\hline 2013 & 36 & 32 & 32 & 39 \\
\hline 2014 & 49 & 46 & 24 & 17 \\
\hline 2015 & 48 & 45 & 40 & 20 \\
\hline Total & 224 & 183 & 152 & 155 \\
\hline
\end{tabular}

\subsection{Evaluation method}

The evaluation criteria were established based on the multispace design model, as shown in Table 2 . Based on the criteria, a list of binary data was built by evaluating the research objects dealt in each article. As an example of the evaluation, Ranscombe, Hicks, Mullineux, et al. (2012) have analyzed the relation between aesthetic features of vehicles and brand recognition by conducting surveys against consumers. Throughout the research, the influence of vehicle visual features (e.g. form of lines and curves, shape of grille and headlamps) on consumer recognition of brand was identified. When looking at this research from the perspective of the evaluation criteria, it can be described that the research has dealt with the relation among "the concept of aesthetics" as the value element, "consumer brand recognition" as the meaning element, "vehicle visual features" as the attribute elements, and "consumers" as the circumstance element. Hence, considering the above characteristic of research objects, a number 1 was given to "value space", "meaning space", "attribute space" and "circumstance", and a number 0 to the rest.

Table 2. Evaluation criteria

\begin{tabular}{c|c|c|l}
\hline \multicolumn{2}{|c|}{ Evaluation criteria } & Definition \\
\hline \multirow{4}{*}{\begin{tabular}{c} 
Thinking \\
space \\
\cline { 2 - 4 }
\end{tabular}} & $\begin{array}{c}\text { Value } \\
\text { space }\end{array}$ & $\begin{array}{l}\text { Deals with an element related to a value for a person or groups, } \\
\text { e.g., a user, a designer, an engineer, a company, society, culture. }\end{array}$ \\
\cline { 2 - 4 } & $\begin{array}{c}\text { Meaning } \\
\text { space }\end{array}$ & Deals with an element related to an image and functionality. \\
Phical & $\begin{array}{c}\text { State } \\
\text { space }\end{array}$ & $\begin{array}{c}\text { Circum- } \\
\text { stance }\end{array}$ & $\begin{array}{l}\text { Deals with an element related to a physical quantity, which are } \\
\text { influenced by the circumstance. }\end{array}$ \\
\cline { 2 - 4 } & $\begin{array}{c}\text { Deals with an element related to a property of surrounding } \\
\text { environment and a user. }\end{array}$ \\
\cline { 2 - 4 } & $\begin{array}{c}\text { Attribute } \\
\text { space }\end{array}$ & $\begin{array}{l}\text { Deals with an element related to a mechanical, geometrical, or } \\
\text { physical property. }\end{array}$ \\
\hline
\end{tabular}

The same approach was applied to rest of the articles and the evaluation results were aggregated for each design domain. Using the results, the percentages of articles which have dealt with each of the evaluation criteria were derived.

\section{Characteristics of domestic research and international research}

Figures 4 and 5 show the result of the evaluation. The column indicates the percentage of articles which deal with each evaluation criteria. 


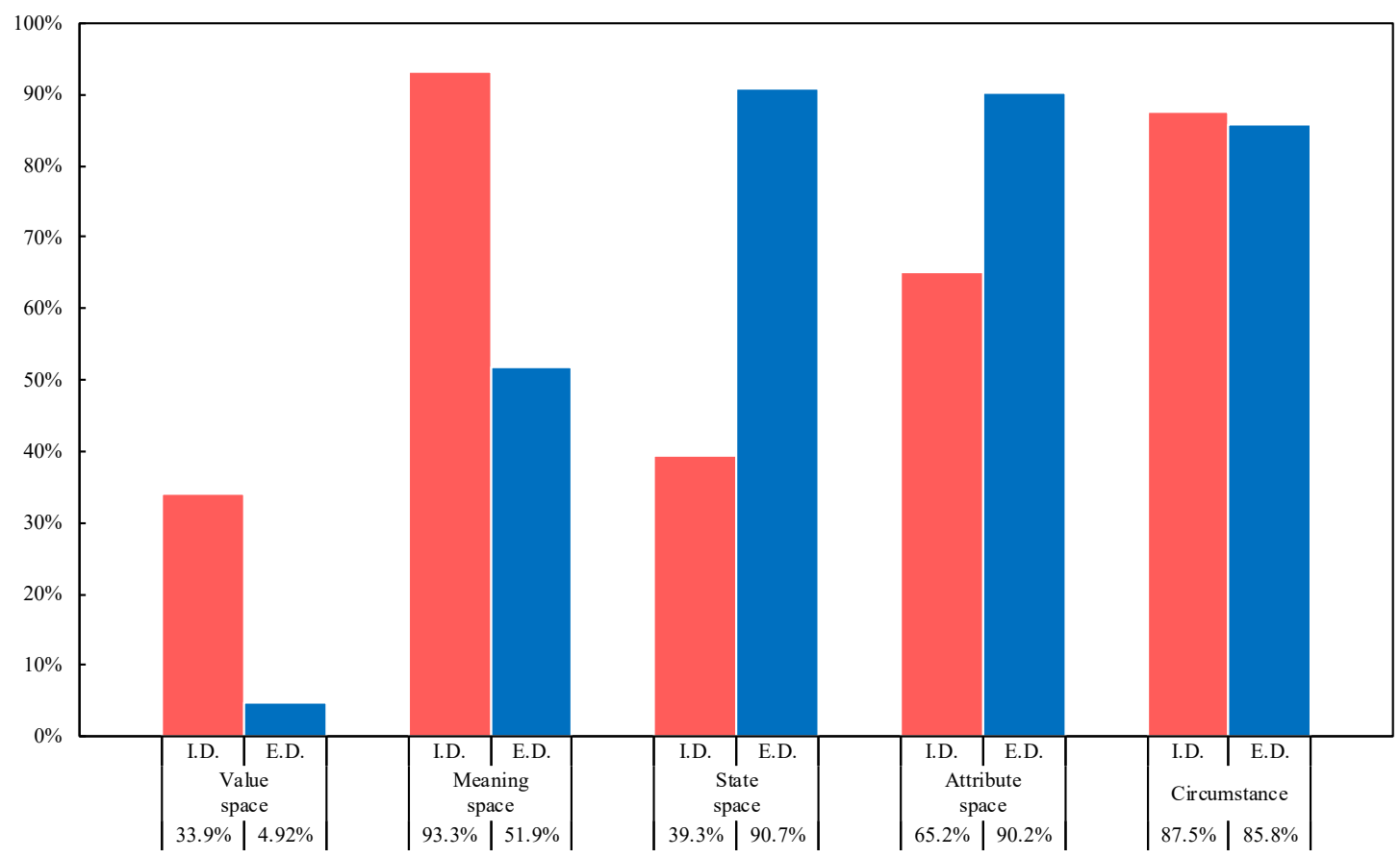

Figure 4. Results of domestic research

\subsection{Characteristics of domestic research}

The percentage of domestic articles in industrial design, which has dealt with the value space, was $33.93 \%$, while that of engineering design was $4.92 \%$. Second, the percentage of domestic articles in industrial design, which has dealt with the meaning space, was $93.30 \%$, while that of engineering design was $51.91 \%$. Third, the percentage of domestic articles in industrial design, which has dealt with the state space, was $39.29 \%$, while that of engineering design was $90.71 \%$. Fourth, the percentage of domestic articles in industrial design, which has dealt with the attribute space, was $65.18 \%$, while that of engineering design was $90.16 \%$. Lastly, the percentage of domestic articles in industrial design, which has dealt with the attribute space, was $87.50 \%$, while that of engineering design was $85.79 \%$.

Consequently, the domestic research for industrial design has mainly focused on the meaning space, the attribute space, and the circumstance. From the result, it can be indicated that many of the industrial design research handle the relation among the images (e.g., "urban looking", "traditional appearance"), the appearance (e.g., colors, shapes), and the properties of users and environments (e.g., age, behaviors, places). One of the possible reasons of why the domestic research for industrial design has dealt with the above elements is because of the actual design convention, i.e., the industrial designers often consider aesthetics in designing based on their own experiences and instincts (Lorenz, 1986; Ulrich and Eppinger, 2008). The way how they work in their practices may have affected the characteristics of the research objects.

On the other hand, the domestic research for engineering design has mainly dealt with the state space, attribute space, and circumstance. This result infers that most of the engineering design research concern with the relation among the physical quantities (e.g., pressure, movement), the physical properties (e.g., materials, structures), and the circumstances (e.g., user properties, road circumstances). In the actual engineering design practice, engineering designers construct physical models with determination of objective functions and constraint conditions. Using the physical models, they adopt optimization approaches to derive the optimal design solution, which is often composed of the configurations and structures of the products (Persson, 2012). These engineering design conventions might have affected the percentage of research object in the research for engineering design. 
In sum, the domestic articles in industrial design have mainly dealt with the meaning space, attribute space, and circumstance, whereas those of engineering design have mainly dealt with the state space, attribute space, and circumstance.

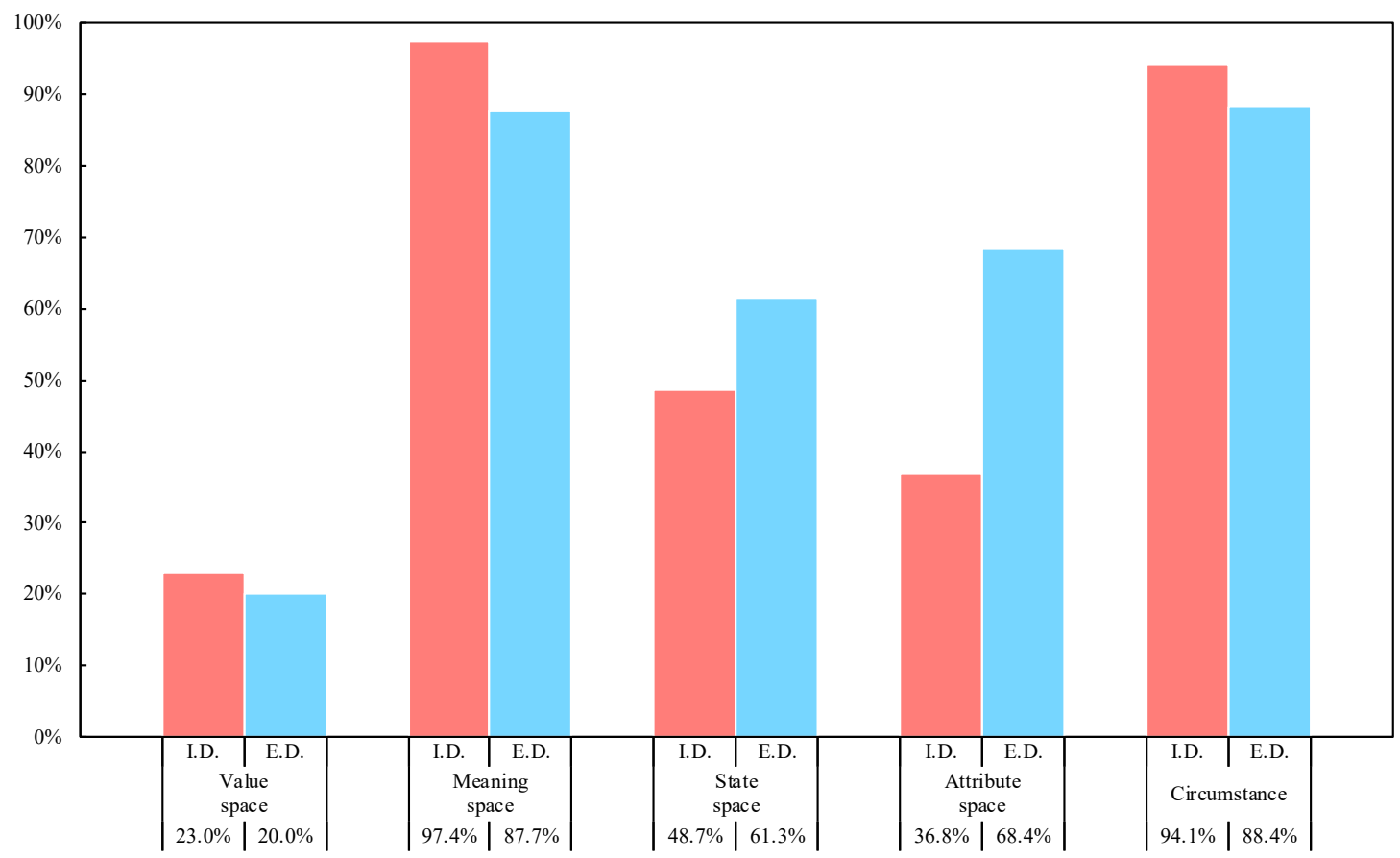

Figure 5. Results of international research

\subsection{Characteristics of international research}

The percentage of international articles in industrial design, which has dealt with the value space, was $23.03 \%$, while that of engineering design was $20.00 \%$. Second, the percentage of domestic articles in industrial design, which has dealt with the meaning space, was $97.37 \%$, while that of engineering design was $87.74 \%$. Third, the percentage of domestic articles in industrial design, which has dealt with the state space, was $48.68 \%$, while that of engineering design was $61.29 \%$. Fourth, the percentage of domestic articles in industrial design, which has dealt with the attribute space, was $36.84 \%$, while that of engineering design was $68.39 \%$. Lastly, the percentage of domestic articles in industrial design, which has dealt with the attribute space, was $94.08 \%$, while that of engineering design was $88.39 \%$.

The results of the international research for industrial and engineering design identified that there were not any distinct differences, as seen in the domestic research. In fact, it can be implied that both have similar characteristics, and thus, the two design domains are almost borderless. The biggest difference was that the percentage of industrial design articles which has dealt with the attribute space was comparatively lower than the research for engineering design. This is possibly because many of the research for engineering design has dealt with establishing new design frameworks (e.g., paradigms, methodologies, design processes) which can be applied to the later process of design; the percentages of industrial design articles which have handled the meaning space and circumstance were distinctively high, possibly from the same reason. On the other hand, the research for engineering design has dealt with almost all of the spaces evenly, except for the value space.

\section{Comparative analysis of domestic and international research}

The followings are the major differences between the characteristics of domestic and international research: 
- The results of both domestic and international research for industrial design show that high percentage of articles have handled the meaning space. But typically, the domestic research seems to deal with the meaning elements related to Kansei, i.e., users' expression of their perceptions toward artifacts, while many of the international research has focused on the functionalities of new design frameworks.

- The percentage of international research for engineering design which has dealt with the meaning space was notably higher than that of domestic research. This is possibly because the domestic research mainly handles optimization problems as their research object, while the international research often focuses on not only the optimization problems, but also constructing new design frameworks (e.g., design theories, design methodologies, design processes).

- As mentioned before, the characteristics of international research for industrial and engineering design are very similar, compared to those of the domestic research. This implies that the two design domains are almost borderless. Specifically, the percentages of international articles which have handled the value, meaning, state spaces and circumstance are almost equal between the industrial and engineering design. On the contrary, the percentages of domestic articles that have dealt with the meaning and state spaces have inverse relation, i.e., the percentage of industrial design articles which focus on the meaning space is distinctively higher than that of engineering design, whereas the percentage of industrial design articles that handle state space are lower than those of engineering design. Therefore, there is a complementary relationship between the domestic industrial design and engineering design. These may have resulted from the fact that the word, "design", is often recognized as the act of considering artifact forms and styles in Japan.

\section{Future issues for design integration}

The characteristics of industrial design and engineering design, as well as their differences have been clarified from the comparative analysis. Based on its results, two main issues to promote design integration have been derived: "collaborative design", and "design engineering". When comparing the two issues, the former intends to expand the fields of each design domain toward the other, meaning that the basic field remains the same, while the latter integrates the both fields to create a unifying domain (Matsuoka, 2010).

"Collaborative design" expects to promote design activities in which the industrial designers and the engineering designers mutually participate, and to integrate each of their design solutions at the late phases of design process. Accordingly, the domestic research for industrial design has mainly dealt with the meaning space, whereas that of engineering design has focused on the state space as its main research object. This result has indicated that there is a complementary relationship between the industrial and engineering design. However, if the both design domains were to work collaboratively, the approaches to easily convert the meaning elements into the state elements (and vice versa) would be necessary. For instance, when designing the appearances of an artifact, it is often important to consider the images the artifact would give to its users, with consideration of surrounding light conditions (e.g., the angle, the color, the movement). Because the images of the artifact are influenced by not only the attribute elements, but also the state elements, it is very important to express the relation of the meaning space and the attribute space with the state space. Consequently, there are only a few articles which has handled such design elements comprehensively. Therefore, this paper suggests against the both industrial and engineering design to advance the investigation of relations between the meaning and the state space as well as to inherit the gained knowledge, for prompting "collaborative design".

"Design engineering" refers to generating a "super designer", who holds broad range of design knowledge. As mentioned in the Section 5.2, the international research for industrial and engineering design appear to deal with almost all the spaces equally. In addition, the research for engineering design seems to practically handle all spaces evenly. These indicates that the international research has been handling wide range of psychological and physical elements as research objects. Such characteristics would be the basis ground to generate a "super designer" and realize the concept of "design engineering". Meanwhile, there were only a few articles which have dealt with the value space. In order to correspond the diversifying user values, generating new values from various perspectives (e.g., users, industrial 
designers, engineering designers, companies, society, culture) are necessary. Hence, the research for both industrial and engineering design must advance the research focusing on the value space.

\section{Conclusion}

This research aimed to clarify the characteristics of industrial design and engineering design by analyzing the domestic and international research for the both domains. In addition, the future issues for facilitating the design integration between industrial designers and engineering designers were investigated. The followings are the gained results:

- The domestic research for industrial design has mainly dealt with the relation among the meaning space, the attribute space, and the circumstance, while that of engineering design has mainly dealt with the relation among the state space, the attribute space, and the circumstance. Furthermore, it was revealed that there is a complementary relationship between the both design domains.

- The international research for industrial design has mainly dealt with the relation between the meaning space and the circumstance, whereas that of engineering design has mainly dealt with nearly all of the spaces, expect for the value space. Accordingly, this implies that there is a borderless relation between the two design domains.

- Two future issues to promote the design integration were derived: "collaborative design" and "design engineering". The former can be solved by inheriting the knowledge of relation between the meaning space and the state space, as well as to construct specific design approaches to replace the meaning elements with the state elements (and vice versa). The latter would be elucidated by advancing the research that deals with all spaces evenly, i.e., the value, the meaning, the state, and the attribute spaces as well as the circumstance. In addition, the necessity of research on the value space in the both societies were pointed out.

This research was limited to analyze the articles published between 2011 and 2015. Thus, the investigation of older articles must be conducted to identify the specific characteristics of both domestic and international research for industrial design and engineering design. In addition, the future analysis could clarify any trends or developments in research by tallying the evaluation results according to each year.

\section{Acknowledgment}

This work was financially supported by the KLL (Keio Leading-edge Laboratory of Science and Technology) 2017 Ph.D. Program Research Grant.

\section{References}

Cross, N. (2008), Engineering Design Methods: Strategies for Product Design, John Wiley, West Sussex.

Hosnedl, S., Srp, Z. and Dvorak, J. (2008), "Cooperation of engineering \& industrial designers on industrial projects", Proceedings of the International Design Conference-DESIGN 2008/Dubrovnik-Croatia, May 19 - 22, The Design Society, Glasgow, pp. 1227-1234.

Jones, J. (2010), Design Methods: Seeds of Human Futures, John Wiley, New York.

Kim, K. and Lee, K. (2010), "Two types of design approaches regarding industrial design and engineering design in product design", Proceedings of the International Design Conference - DESIGN 2010/ DubrovnikCroatia, May 17 - 20, The Design Society, Scotland, pp. 1795 - 1806

Kim, K. and Lee, K. (2014), "Industrial designers and engineering designers; causes of conflicts, resolving strategies, and perceived image of each other", Proceedings of DRS 2014, Design Research Society, Aston-onTrent.

Kim, K. and Lee, K. (2016), “Collaborative product design processes of industrial design and engineering design in consumer product companies", Design Studies, Vol. 46, pp. 226-260. https://doi.org/10.1016/j.destud.2016.06.003

Lee, W. (1995), "Identifying the attributes of designers' thinking in the design process: Research on design thinking”, Bulletin of JSSD, Vol. 42 No. 4, pp.57 - 66. https://doi.org/10.11247/jssdj.42.57_2

Lorenz, C. (1986), The Design Dimension, Basil Blackwell Ltd. New York.

Matsuoka, Y. (2010), Design Science - “Six Viewpoints” for the Creation of Future, Maruzen, Tokyo.

Matsuoka, Y. (2012), "Multispace design model towards integration between industrial design and engineering design”, Proceedings of DRS 2012, Design Research Society, Aston-on-Trent. 
McMahon, C. (2012), "Reflections on diversity on design research", Journal of Engineering Design, Vol. 23 No. 8, pp. 563-576. https://doi.org/10.1080/09544828.2012.676634

Persson, S. and Warell, A. (2003), "Relational modes between industrial design and engineering design: A conceptual model for interdisciplinary design work", Proceedings of the $6^{\text {th }}$ Asian Design International Conference, ADC, Tsukuba.

Ulrich, T. and Eppinger, D. (2008), Product Design and Development, McGraw-Hill, New York.

Yoshikawa, H. (1979), "Introduction to general design theory", JSPE Journals, Vol.45 No.8, pp.906-912. https://doi.org/10.2493/jjspe1933.45.906

Yoshikawa H. (1981), "General theory of design process", JSPE Journals, Vol.47,No.4, pp.405-410. https://doi.org/10.2493/jjspe1933.47.405

Yoshikawa H. (1985), "General design theory”, Science of Machine, Vol.37 No.1, pp.108-116.

Yuma Sakae, Ph.D. candidate

Keio University, Graduate School of Science and Technology

3-14-1 Hiyoshi, Kohoku-ku, 223-8522 Yokohama, Kanagawa, Japan

Email: yuma.sakae0831@gmail.com 